Article

\title{
Carbon Ruins: Engaging with Post-Fossil Transitions through Participatory World-Building
}

\author{
Johannes Stripple ${ }^{1}$, Alexandra Nikoleris ${ }^{2, *}$ and Roger Hildingsson ${ }^{1}$ \\ ${ }^{1}$ Department of Political Science, Lund University, 22100 Lund, Sweden; E-Mails: johannes.stripple@svet.lu.se (J.S.), \\ roger.hildingsson@svet.lu.se (R.H.) \\ 2 Department of Technology and Society, Lund University, 22100 Lund, Sweden; E-Mail: alexandra.nikoleris@miljo.Ith.se \\ * Corresponding author
}

Submitted: 3 November 2020 | Accepted: 25 February 2021 | Published: 28 April 2021

\begin{abstract}
While many pathways to post-fossil futures have been articulated, most fail to engage people in imagining themselves as being part of those futures and involved in the transition. Following recent calls for more immersive experiences, the 2019 initiative "Carbon Ruins-An Exhibition of the Fossil Era" (Carbon Ruins) is a performance set around a historical museum from the future, which uses recognisable, culturally powerful physical objects to bridge the gap between abstract scenarios and everyday experiences. Through its physical presence and extensive media coverage, Carbon Ruins struck a chord with scientists, activists, creative professionals, policy makers, civil society organisations, and the general public. Like other imaginary worlds, Carbon Ruins is not finished. It is an open-ended process of narrating, imagining, and representing (the transition to) a post-fossil future. In this article we reflect upon Carbon Ruins as a participatory form of world-building that allows for new ways of knowing, and new ways of being, in relation to post-fossil transitions. We discern three different kinds of authorship that were taken on by participants: as originators, dwellers, and explorers. While the originator makes the future world a recognisable place, the dweller can engage active hope in place of a passive sense of urgency, and the explorer can transform resignation into commitment, with a fresh determination to leave the fossil era behind. Situating Carbon Ruins within a critical political tradition, we find post-fossil world-building to be a form of critique that destabilises accustomed ways of thinking and opens up new fields of experience that allows things to be done differently.
\end{abstract}

\section{Keywords}

critical practice; experiential futures; imagination; post-fossil futures; world-building

\section{Issue}

This article is part of the issue "Is There a New Climate Politics? Emergency, Engagement and Justice" edited by Anna R. Davies (Trinity College Dublin, Ireland), Stephan Hügel (Trinity College Dublin, Ireland) and Vanesa Castán Broto (University of Sheffield, UK).

(C) 2021 by the authors; licensee Cogitatio (Lisbon, Portugal). This article is licensed under a Creative Commons Attribution 4.0 International License (CC BY).

\section{Introduction}

The year is 2053. The curator at the recently inaugurated museum Fossil opens:

Welcome to the Carbon Ruins exhibition! It is created to act as a form of collective memory from the fossil era, and as a space in which to discuss what living sustainably in a post-fossil society actually means.
The exhibition is also a way to celebrate that we were successful in limiting global warming to 1.5 degrees and reaching our net zero emissions goal three years ago. Here in Sweden, we are proud to have been the first-and not just first, but early! We hit zero emissions back in 2045, in accordance with the climate laws laid down in the twenty-tens. I think we deserve a little bit of applause for that, don't you?

\footnotetext{
*applause*
} 
It is well understood that imagination is crucial for societal transformations (e.g., Ghosh, 2017; Linnér \& Wibeck, $2019,2020)$. How we imagine the future shapes the choices we make in the present and, conversely, our failure to imagine alternative futures hampers us in organising society differently (Andersson, 2018; Beckert, 2016). Transitions to post-fossil futures are imagined through a range of different means, such as emissions trajectories, energy scenarios, industry road maps, and long-term climate policy strategies. These have, however, largely failed to meet the world as it is now, or tell us about how we will inhabit future worlds. Transitions become intangible, abstract, and out of reach for citizens and organisations. So, despite the proliferation of scenarios and visions, and assurances that, for example, the EU will be climate neutral by 2050 through a new Climate Law, we still know very little about how such an imagined postfossil world works, and how we get there. We are not drawn into these post-fossil worlds in the same way as we are immersed in Tolkien's, LEGO's, or Minecraft's. But why is that? Shouldn't it be possible to tap into the joy of inventing, building, and visiting imaginary worlds as a way to wrestle with the inertia and path dependencies that lock us into high-carbon economies (Bernstein \& Hoffmann, 2019)?

We take, as a starting point, inspiration from Levitas (2013)-utopia as emergent expressions of a better world-to explore how imaginary worlds that are still open and 'unfinished' can enable participants to craft stories about a transition that are compelling for other people. What bearing speculative post-fossil world-building could have on the conceptual and theoretical work of academia might not be immediately obvious. But interventions like "Carbon Ruins-An Exhibition of the Fossil Era" (hereafter Carbon Ruins) can be seen as having a methodology that resembles 'critical environmental politics,' broadly conceived: They seek to make the familiar appear strange, and so bring the unfamiliar into clearer focus (Death, 2014, p. 1). By destabilising our accustomed ways of thinking, such interventions clear a space for things to be otherwise (Burchell, 1996, p. 33). Climate imagination can thus be a critical practice that seeks to "gain clarity about the conditions under which we think and act in the present" (Dean, 2004, p. 36). By problematising what is given to us as necessary to think and do, Carbon Ruins aligns with more familiar modes of critical scholarship such as those emanating from Marx, Gramsci, the Frankfurt School, or post-structuralism. But the insistence of Carbon Ruins on staging a speculative immersive experience is something it shares with many works of visual and performance art. Thus, we find post-fossil world-building, along the lines we develop in Carbon Ruins, to be a form of critique that calls for playfulness and experimentation with possible spaces of transformation. Our ambition with Carbon Ruins echoes Foucault's epistemological gesture, that "knowledge is not made for understanding; it is made for cutting" (Foucault, 1984, p. 88).
Departing from a Rancièrian account of politicsone that opens up new spaces, possibilities and conversations-Candy (2010) suggests that we need critical futures thinking in order to move beyond a 'politics of the obvious' and deliberately craft moments where the world could be seen and experienced otherwise. Design and fiction are hence indispensable tools for engaging politics. In this aesthetic register, some ways of seeing or doing are made visible, thinkable, or available in a way that they previously were not (Candy, 2010, p. 130). The problem, however, according to Candy, is that our performative and material practices for thinking possible worlds 'out loud' are underdeveloped. We need to design and stage interventions that:

Exploit the continuum of human experience, the full array of sensory and semiotic vectors, in order to enable a different and deeper engagement in thought and discussion about one or more futures, than has traditionally been possible through textual and statistical means of representing scenarios. (Candy, 2010, p. 3)

Hence, the political needs not just to be interpreted, but enacted through a variety of material and aesthetic forms.

In 2019, scholars associated with Lund University developed Carbon Ruins. The world of Carbon Ruins was represented as a historical exhibition in the Swedish museum Fossil. Through a range of objects, narratives, performances, and images, the museum evidences how humanity finally responded to intensifying climate disruption. The aim is to inspire hope in the early-21stcentury visitor that a post-fossil transition is possible, if neither simple nor without loss. The collection and the interactive elements of Carbon Ruins frame transition in the past and 'future present' as a process that has already happened. Remnants and artefacts of the highcarbon era are displayed alongside accounts of their journey to obsolescence, a presentation that estranges them from their original context and instead makes them visible as carbonised objects and agents of climate injustice. Remember frequent flyer cards? Beef burgers? Plastic toys, steel bottles, and concrete infrastructures?

Despite the overarching frame narrative that forms the backbone of Carbon Ruins - that we did indeed manage to meet the Paris Agreement target of limiting global warming to 1.5 degrees - Carbon Ruins is not told as a single story. In that sense, its features most resemble what Wolf (2012) calls 'imaginary worlds.' While all the different elements of Carbon Ruins contribute to the making up of a post-fossil world, they are not there simply to advance the story of how we transitioned away from the fossil era. Rather, they invite the participant to actively immerse themself into that world and become part of it, in order to remember the losses and sacrifices, the feel and smell of things lost or left behind, and the joyous moments once the transition was well under way. 
To catalyse engagement with climate politics, we discuss in this article the potential of depicting post-fossil transition as culture, rather than technology; and as experience, rather than as policy scenarios and industrial visions. We reflect, in particular, upon Carbon Ruins as a participatory form of world-building that allows for new ways of knowing, and new ways of being, in relation to post-fossil transitions. Following this introduction, in Section 2 we introduce the concept of 'world-building,' and discuss how imaginary worlds could be developed and used. We describe how the Carbon Ruins world was made and how it continues to expand, still being added to and coming to life in new ways. In Section 3 we articulate three different kinds of authorship that participants engaged in, and what that meant for the ways in which Carbon Ruins spurred new kinds of conversations on climate change and post-fossil transitions. Finally, we reflect on our experience of creating imaginative spaces that could be inhabited by various publics, and the kinds of engagement with a post-fossil world it gave rise to among participants.

\section{Imaginary Worlds}

The process of constructing an imaginary world is often called world-building. This work takes a number of forms today, including science fiction novels, video games, and energy projections. Key to the success of a worldbuilding project is an imaginary setting that is coherent in its ecology, its geography, and its cultural features, including its politics. Humans' ability to simulate situations has guided our evolution throughout history (Holland, 2009). When responding to imaginary worlds, we engage both abstract thought and emotion, to vividly simulate what is not but might be. The study of such worlds has a long tradition in literary theory, media studies, anthropology, sociology, international relations, and more. Insights drawn from across this wide field of study helped us find our point of departure with Carbon Ruins. Weldes (2003, p. 11) calls for a study of politics that uses 'possible worlds' to "explore elements of contemporary society in more or less estranged settings." Crawford (2003, p. 209) draws attention to the close affinity between critical theory and science fiction, where our present is destabilised through utopian science fiction's narrative techniques of extrapolation, estrangement, and defamiliarization. The development of specific utopian visions is the necessary first step towards identifying the obstacles to social and political change. Feminist utopian science fiction with its insistence on emotional engagement, passion, and hopeful reconstruction, is an example of a fertile ground on which to remake world politics (Crawford, 2003). Similarly, Nordin (2010, p. 110) relates science fiction writing to the long tradition of the thought experiment in analytic philosophy. He cites in particular the Foundation trilogy of Isaac Asimov and the Mars trilogy of Kim Stanley Robinson, calling for a philosophy of 'meaningful speculation' for which fiction can be a powerful tool.

Literary scholars have stressed the importance of authenticity in imaginary worlds. As Tolkien put it, in order for an imagined world to read as credible, it must be presented 'as true' (1947). Suvin (1979) argues that the genre of science fiction uses a variety of tropes and techniques to generate the necessary 'cognitive dissonance' to project its audience into an imagined alterity or futurity. Expanding on this, recent work in the emerging field of design fiction (Candy, 2010; Candy \& Dunagan, 2017), as well as work within media studies (Wolf, 2012) have drawn attention to the particular qualities of worldbuilding - the shift from story to world. The best imaginary worlds have an open-ended, work-in-progress quality. Think, for example, of Star Trek, which has unfolded across decades and diverse media-film, TV series, video games, and so on. As Jenkins puts it, "we are drawn to master what can be known about a world which always expands beyond our grasp" (2007, as cited in Wolf, 2012, p. 11). Following Wolf (2012, p. 17), the imaginary world of Carbon Ruins is a realm of possibility, a mix of the familiar and unfamiliar, of dread and dream, that can make us more aware of the circumstances of the actual world we inhabit. Carbon Ruins is multi-authored, with new stories perpetually being made about places, characters and agents of change. Such a mode of engaging with postfossil transitions through participatory world-building is what makes Carbon Ruins distinct from other future exercises and thus worth exploring in more detail.

In recent years, representations of a climate-changed world have proliferated in the forms of art installations, literature, movies, exhibitions, and games. Some of these emanate from the cultural and creative sector, others from within academia, urban planning, or the media industry. Representing this wider production of 'climate imaginaries' is beyond the remit of this article, but a few examples are introduced as context. Hajer and Pelzer (2018) ran a staged performance of a multimedia installation that tells a story of the large-scale exploitation of the North Sea for harvesting offshore wind energy, and Pelzer and Versteeg (2019) facilitated a contest that concerned imagining a post-fossil city. A wide range of immersive and interactive art installations have nurtured alternative forms of world-building (see, e.g., Bendor, Maggs, Peake, Robinson, \& Williams, 2017), while Robinson (2003), Wangel (2012), Candy and Dunagan (2017), Hesselgren, Eriksson, Wangel, and Broms (2018), and Wangel et al. (2019) have experimented with new forms of participatory future-making. There is more analysis to be done on the features that these projects of climate-change world-building have in common and the differences between them. Our preliminary view is that these examples represent instances of pluralistic and performative anticipatory approaches to climate governance (Muiderman, Gupta, Vervoort, \& Biermann, 2020). 


\subsection{Making the Carbon Ruins World}

Carbon Ruins opened on 8th April 2019 at Lund University (see Figure 1). To engage with different audiences, it toured around Lund, hosted by the Town Hall in May, the Cathedral Visitors' Centre in September, and the Public Library in October. The exhibition was guided over 100 times and visited by nearly 6,000 people in 2019. Following requests to display the exhibition in other venues, a mobile version was developed in the summer of 2019, housed in a 100-year-old trunk that has retained its original appearance (see Figure 2). Since October 2019, the trunk has been on display locally in Lund as well as in other cities in the south of SwedenMalmö, Växjö, and Helsingborg. Plans for displaying it in Stockholm had to be relinquished due to the Covid-19 pandemic, but since the autumn of 2020 Carbon Ruins appears as part of the "Human Nature" exhibition at the National Museums of World Culture in Stockholm. In March 2020, a digital audio guide app was developed, which allowed for an immersive experience that could either accompany, or function independently of, the exhibition.

Wolf describes the way imaginary worlds come to life across different media and story arcs, "grow[ing] in clarity and detail, inviting us to enter and tempting us to stay, as alive in our thoughts as our own memories of lived experience" (Wolf, 2012, p. 2). In Carbon Ruins the device of a fictional museum exhibition is deployed to produce a sense of the present as the future's past. The museum, being a site of shared public memory, is a format of many useful rhetorical capabilities. The audience already knows what to expect from a museum. They have a prior relationship with the format that helps visitors make the imaginative leap into the present as past. Each 'portal' object contains information elements-the look of a fast-food burger, the feel of plastic turf, or a narrative of how locals formed a new sustainable mining business - that add detail to the imaginary world.

A basic frame narrative tells us that the year is 2053, that we are in Sweden, and that we met the Paris Agreement target of limiting global warming to 1.5 degrees. A brief outline of what this means for Sweden, in terms of local climatic changes (e.g., increased risk of forest fires and changes to the length of seasons), sets the world parameters with which all other elements of Carbon Ruins have to be consistent. From January to March 2019, we hosted scenario workshops and conversations with experts and practitioners in the areas of energy, steel, plastic, mobility, and agriculture to produce the first building blocks of this world. Participants were introduced to the frame narrative and given the task of reflecting on current practices or objects that would have changed or become obsolete in the Carbon Ruins world. They were also asked to speculate how that transition happened, why particular objects disappeared, who the agents of change were, and which key events would structure the story of that

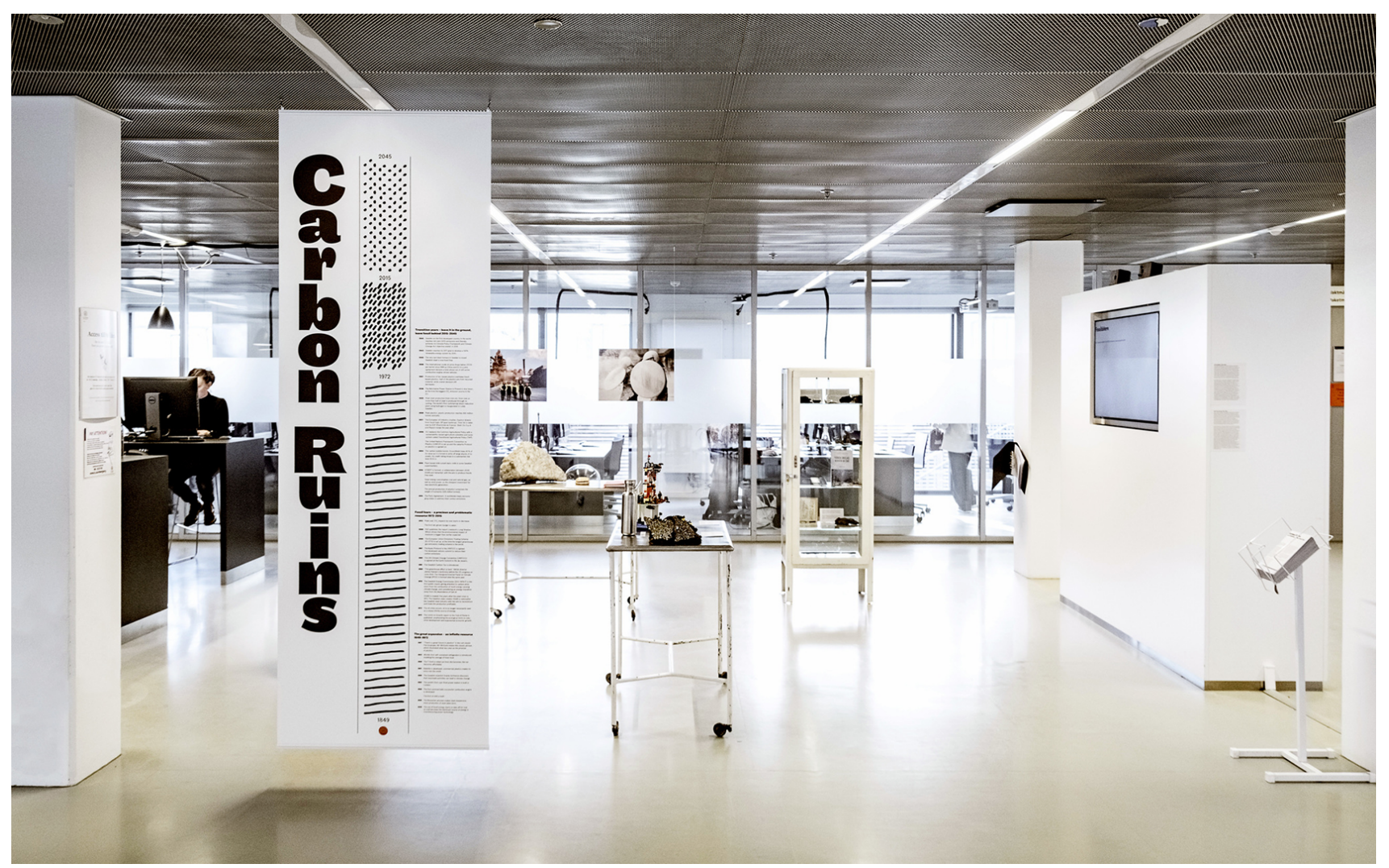

Figure 1. Carbon Ruins at Lund University. Photography by Håkan Röjder (8 April 2019). 
change. A core group, which included the authors of this article, then designed the formal exhibition architecture and curated the objects.

Another key world-building block is a large canvas timeline of the fossil era (1849-2049), which highlights three (fictional) historical periods: the years of Great Expansion, the years of Fossil Fears, and the Transition years.

Key speculative events in the Carbon Ruins story are the bursting of the global carbon bubble in 2024, the introduction of the EU Transitional Agricultural Policy in 2026, the decommissioning of the Bełchatów coal-fired power plant in 2036, and the closure of the last blast furnace in Sweden in 2042. Stepping into the exhibition, participants encounter a selection of artefacts that draw attention to the changing practices that have made these objects obsolete. Some objects, such as minerals used for electric vehicles, or bumblebees and beetles, bring attention to sustainability challenges that might remain, or are even intensified, in a post-fossil future.

Participants were invited to send written questions and reactions to the exhibition's email address. They could take guided tours, in which the guide prompted them to immerse themselves in the world by imagining who they were in 2053 and what they did during the transition years (photographs from two such guided tours can be seen in Figure 3). In this way, a tool for time travel was provided to the participants. Acting as guides, scholars from the core group guided visitors through the exhibition and introduced them to the objects on

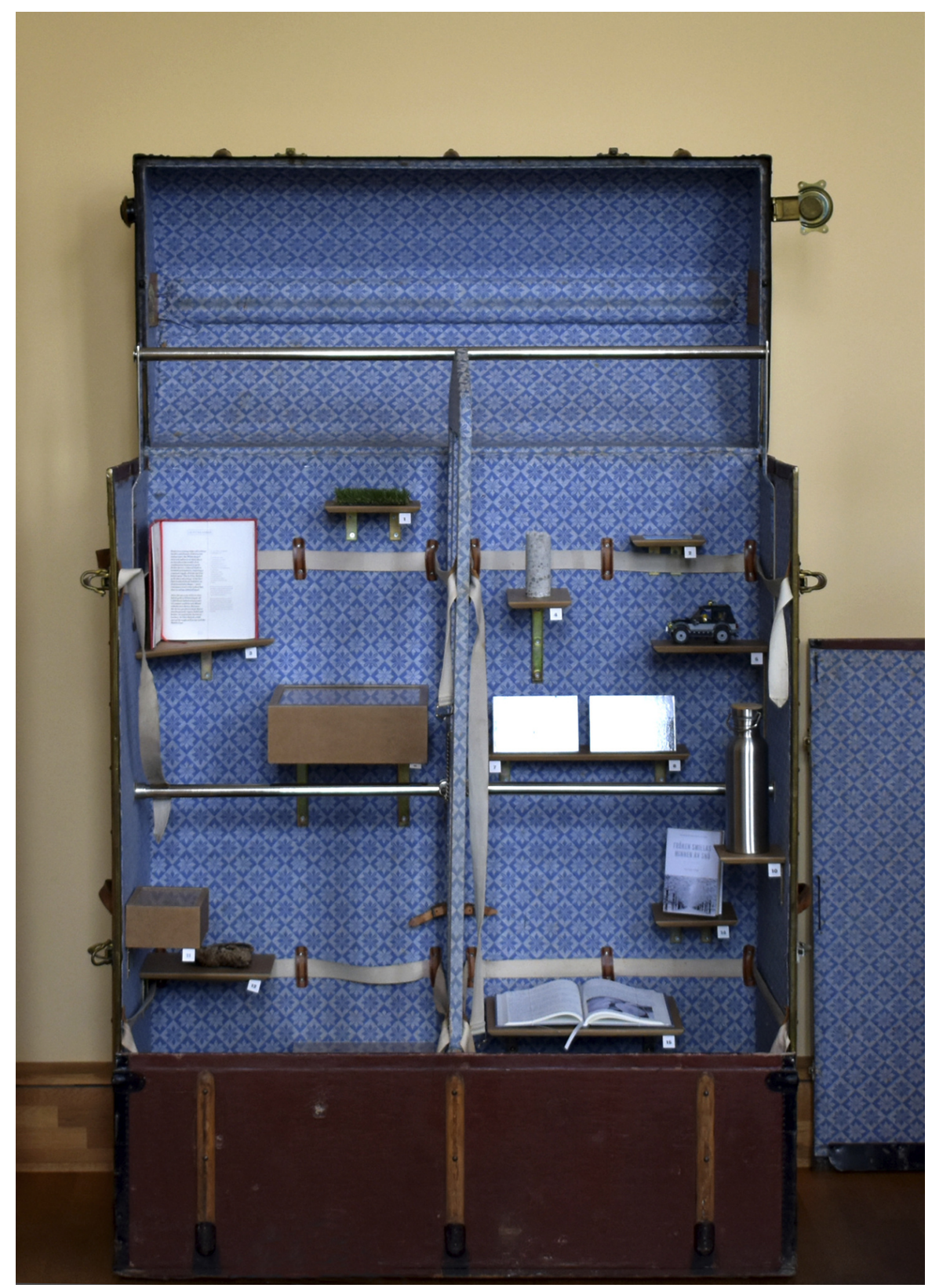

Figure 2. The mobile version of the Carbon Ruins exhibition. Photography by Ludwig Bengtsson Sonesson (24 October 2019). 

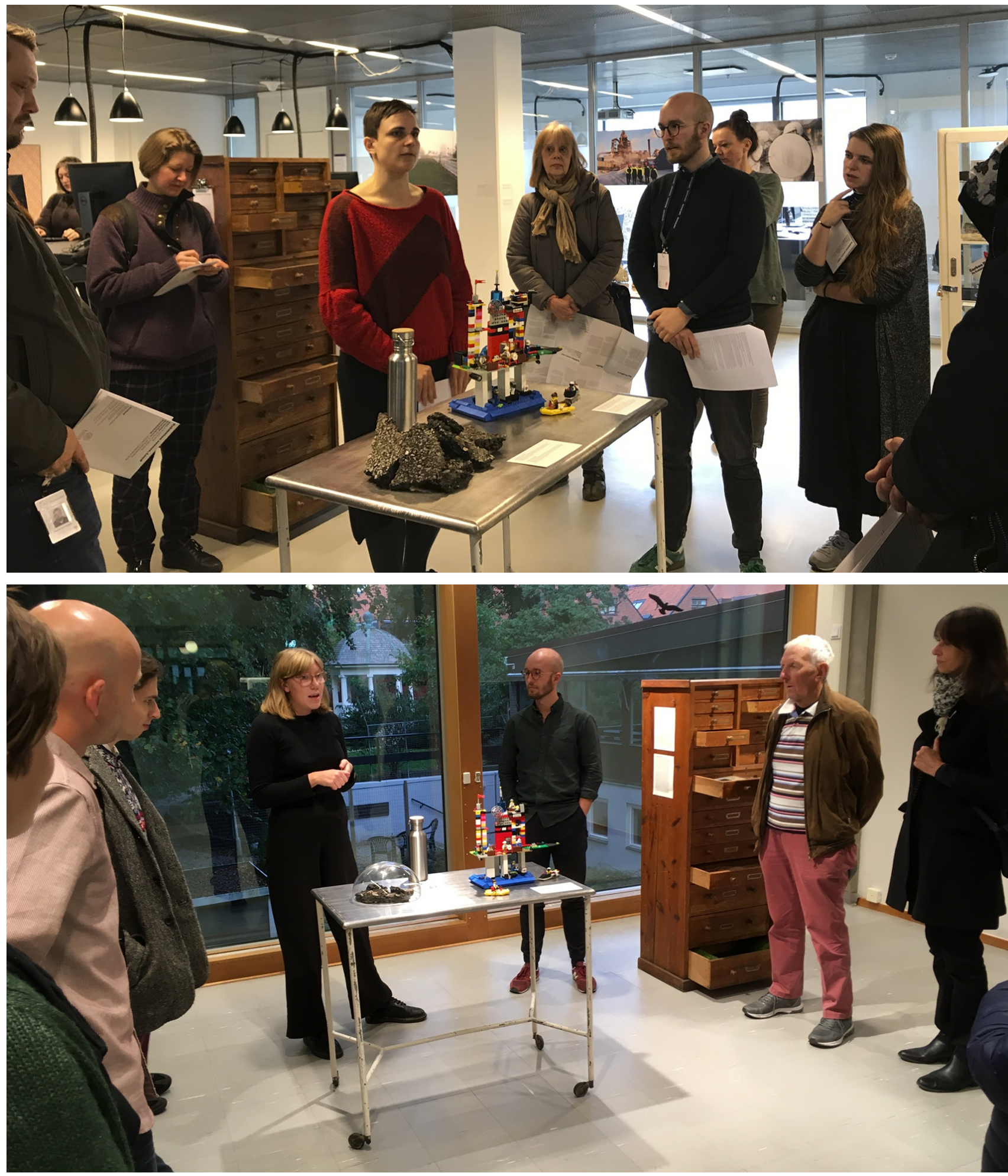

Figure 3. Guided tours at different locations. Lund University (top), public library (bottom). Photographs by Caroline Mårtensson (top; 8 April 2019) and Roger Hildingsson (bottom; 10 October 2019).

display by narrating the role each played in the transition, what made them change, and who the agents of change were. The guided tours also created room for conversation and dialogue between the narrators and the visitors. The stories being told were deliberately not too fixed, but were left intentionally open to spark vis- itors to react, ask questions, and intervene-from the perspective of their future selves. Visitors' comments and imaginative reactions were picked up on and sometimes incorporated into the storytelling in subsequent tours. After every guided tour, some time was spent out of character to allow the participants to ask ques- 
tions and leave suggestions as to how to further develop the exhibition.

This feature was further developed into fictional storycrafting workshops in which participants were asked to craft their own stories about the transition years. These workshops turned out to be critical for the expansion of Carbon Ruins, but also for nuancing what it means to participate in this world. Workshops were carried out with a wide range of participants, including visitors at public events, scheduled groups, researchers, and students. We also held one participatory performance in which the acquisition of a new exhibit was staged in character.

The Carbon Ruins world is based not on individual characters or a specific plot, but on a mix of elements-or sub-worlds-which can sustain multiple interrelated characters and their stories. This process of world-building encourages the audience's curiosity about "a world which always expands beyond our grasp" (Jenkins, 2007, as cited in Wolf, 2012, p. 11). Like other imaginary worlds, Carbon Ruins is not finished. It is an open-ended process of narrating, imagining, and representing (the transition to) a post-fossil future. At all the sites, events, and interventions, participatory worldbuilding took place. Because of its participatory performance character, Carbon Ruins is also a world that evolves, making it able to represent many different, though similar, futures. New objects and stories are continually being added, while others are changed or removed. Everyone who visits Carbon Ruins is thus considered a co-author in the work of world-building. While some have contributed extensive story-making and research, others have contributed a question or a nod of recognition which, however simple a gesture, nevertheless involved them in the shared imaginative project. To participate in Carbon Ruins is thus an exploratory as well as a co-creative exercise, and a cross-learning experience. The more actively you participate, the more you learn about and shape the world.

\section{Ways of Knowing, Ways of Being: How People Engaged with Carbon Ruins}

Carbon Ruins allows for physical immersion in the postfossil world of 2053. In the museum, the visitor is surrounded by objects that belong to an era that is now gone, creating a sensory and conceptual immersion by which the participant becomes mentally and emotionally involved. The aim of the Carbon Ruins project was, however, to go beyond mere immersion and allow people to actively contribute to the world, so as to find their own place in the transition. Allowing visitors to add objects to the collections, and to invent and share new stories, makes the transition tangible and populates it with characters that people can relate to and identify with.

Our reflections on the kind of engagement with climate politics and governance this participatory worldbuilding allows are based on participatory observation at the different sites and events that we have hosted, from the first world-building exercises to the guided tours and workshops. As guides of the exhibition, we interacted with the participants in different ways. We prompted them to imagine their (fictive) experiences of the transition years and answered spontaneous questions. Reactions and questions out of character were also common. Short notes of notable, recurrent, or unusual responses and remarks were written down after each guided tour or storycrafting workshops. Follow-up interviews were made with participants who had been more heavily involved in the world-building by participating more than once, actively inviting members of their own organisations to take part, or hosting the exhibition and so becoming co-organisers of the world-building. In total, five interviews were made. Four of them were individual interviews - two policy officers from Lund municipality and two officers from the Swedish Church-and the fifth was a focus group interview with three people from a traffic consultancy firm engaged in planning and sustainable mobility. As the Carbon Ruins project was heavily reliant on this kind of collaboration, we wanted to know why these people had chosen to bring the exhibition to their respective organisations, what expectations they had, and what it had meant for them as individuals as well as professionals. We also asked them if Carbon Ruins had somehow influenced the way their organisations were thinking about or working towards post-fossil transition.

Reflecting on our experiences and interactions during workshops, guided tours, and follow-up interviews, we discern three different kinds of authorship among the ways in which participants engaged with Carbon Ruins. Participants fell into the categories of originators, dwellers, and explorers. These authorships represent different positions taken when contributing to the worldbuilding and should not be seen as fixed categories; a given participant might contribute as originator and as explorer, sometimes in the same world-building exercise. Although the world-building process of Carbon Ruins was open, it necessarily went through different stages that allowed different kinds of opportunities for participation and contribution. In the following section, we elaborate on how the different forms of authorship build bridges between current everyday worlds and the future; that is, how they make transitions tangible and relatable, and let people see themselves in that future world. We describe how the staging of different activities allows for the creation of different forms of authorship, and what these imply in terms of: (1) what questions were asked about, and in, the Carbon Ruins world; (2) the typical contributions of each type of author; and (3) the kinds of affective engagements these give rise to (see Table 1).

\subsection{Originators}

The originators were the first to inhabit the Carbon Ruins world. They produced the timeline, encyclopaedic content like newspaper clippings, and research papers from 
Table 1. Modes of engagement for different kinds of authorship.

\begin{tabular}{lllll}
\hline & Key questions & Ways of participating & Kinds of contributions & Affective engagement \\
\hline Originators & $\begin{array}{l}\text { What objects or } \\
\text { practices were left } \\
\text { behind in the post-fossil } \\
\text { transition? Why where } \\
\text { they left behind? }\end{array}$ & $\begin{array}{l}\text { Workshops, meetings, } \\
\text { study visits }\end{array}$ & $\begin{array}{l}\text { Objects, stories, } \\
\text { encyclopaedic content }\end{array}$ & $\begin{array}{l}\text { Enthusiasm, creativity, } \\
\text { knowledge deployment, } \\
\text { speculation }\end{array}$ \\
Dwellers & $\begin{array}{l}\text { What do you recognise? } \\
\text { What do you }\end{array}$ & $\begin{array}{l}\text { Guided tours, visits, } \\
\text { audio guide, media } \\
\text { remember? What does } \\
\text { all this mean? }\end{array}$ & $\begin{array}{l}\text { Reactions, questions, } \\
\text { coflections, added } \\
\text { detail, } \\
\text { contextualisation }\end{array}$ & $\begin{array}{l}\text { Humour, play, } \\
\text { imagination, personal } \\
\text { stake, objections, hope }\end{array}$ \\
& $\begin{array}{l}\text { What is missing? What } \\
\text { do you challenge? }\end{array}$ & $\begin{array}{l}\text { Workshops, } \\
\text { interventions, hosting } \\
\text { the exhibition }\end{array}$ & $\begin{array}{l}\text { More stories, more } \\
\text { objects, and alterations } \\
\text { (challenging details or } \\
\text { larger parts) }\end{array}$ & $\begin{array}{l}\text { Hope, pathways to } \\
\text { change, ownership }\end{array}$ \\
& & & &
\end{tabular}

the future. They also devised stories of objects that disappeared or changed during the transition years. Most of the participants who took the role of originator were researchers or experts in relevant fields, participating in the initial world-building workshops together with the core group. They had typically not seen any of the other elements, as the Carbon Ruins world at that stage was yet to be constructed. The originators therefore did not have access to an already-existing imaginary world, or even parts of it. Important prompts that facilitated their engagement with the world-building exercise were the frame narrative, with its implications for Sweden and for specific sectors, and draft versions of the timeline. Their reactions to these were considered and incorporated into the imaginary world that was then coming into being. Drawing on their knowledge, expertise, and lived experiences, participants were invited to identify objects and practices that might be left behind or become substantially transformed in the transition, and to craft their own stories about what happened during the transition years.

As originators, they engaged with the task at hand with enthusiasm and creativity, and enjoyed the chance to apply their expertise and knowledge to speculative thought. Many even took the chance not only to leave behind undesirable objects and practices in the fossil era, but also to think about a better world to come. A common thread of wishful thinking and moral utopianism can be found in many of the originator stories. Without any sophisticated problematisation or further substantiation, many things were solved simultaneously by the transition to a future that was not only post-fossil but also resembled a near-perfect future society. The fossil era was looked back on not only as the period when human activity heated the Earth, but as an era of unsustainability in which we humans were unhealthy, wasteful, disconnected from nature and our senses, and so forth. This moral utopianism is not uncommon, and can be seen in other scenarios, but is contradictory to the pluralism strived for in critical utopianism. It is also less produc- tive for building an imaginary world inhabited by persons characterised by all the shortcomings and deficiencies of human individuals. All this points to the challenges of engaging in imaginary thinking and meaningful speculation about a world yet to be. It is no simple matter to craft stories that are coherent and credible to various publics intended to inhabit such an unfinished world.

Not unexpectedly, many of the first stories developed were full of unsolved questions, inconsistencies, and loopholes, and fairly closely resembled the present world with its comfortable familiarity. An interpretation of the somewhat conservative first efforts of many originators is that, having no world to relate to but the present, the originators were searching for the Carbon Ruins future by grounding it in past and contemporary debates with which they were familiar. This is, however, an important facet of making a world which is felt as 'real.' The originator stories illustrate how this kind of authorship contributes to bring the imaginary world to life in the present by balancing novelty with plausibility. While dramatic and playfully exaggerated, many originator stories took inspiration from present phenomena, such as: the Liberate Tate performances at Tate Modern (the LEGO protests story); farmer demonstrations in Brussels and Paris (the milk riots); WW2-era practices of rationing and collective efforts (the steel crisis); or even inventing a fictive sequel of an acclaimed novel to show how language was once permeated by fossil fuel use (Miss Smilla's Memories of Snow). Stories like these added recognition, authenticity, and credibility to the processes of change in the Carbon Ruins storyworld. They made a post-fossil world feel like a plausible outcome, but showed that there were conflicts and strong emotions that emerged along the way.

\subsection{Dwellers}

Dwellers were more diverse in their engagement with Carbon Ruins than the originators. Entering into an 
already existing but unfinished world as visitors and participants, they could react to, and expand on, the things they encountered. One participant reflected that the timeline, through its extension into the future, linked the Carbon Ruins world to the present and past, which made the immersion easier. Participants at the dweller stage were asked to recount (that is, invent) their own experiences of the transition years. Their imaginative engagement gave a new vividness to the Carbon Ruins stories that the originators had invented. As one of the interviewees expressed it: "Reality and imagination are blurred. That is what makes it different. Imagination is what makes it exciting. It also invites participants to dare speculate, and to dare move the boundaries for what is possible" (Policy officer, Lund municipality).

The immersion was not always an easy or leisurely one. It provoked a range of emotional responses. A few objects and their stories were particularly powerful for reflection on the personal stakes of a post-fossil transition. One participant said she experienced a kind of crisis when hearing the nylon stockings story, emphasising the carbon embedded in the nylon fabric: "So I'm, like, wearing oil? I have never thought about it that way" (anonymous person at one of the guided tours in Lund). Changed conditions for travel and leisure, in response to both mitigation strategies and a changing climate, were mourned. When listening to the story of how professional sportspeople protested climate change inaction by demonstrating how the conditions for winter sports were rapidly deteriorating, one participant painfully recounted a memory of the first time there was not enough snow at his favourite ski resort in Austria. This story, together with that of the frequent flyer card, also prompted reflections on the status travel has and what it means: "We live to travel. The trip really starts six months earlier. What is the meaning of life if we cannot travel? To show the kids: This is where we are going, that is when we will be happy!" (Policy officer, Malmö municipality). But anger was also provoked by the frequent flyer card because it belonged to a climate researcher. One participant countered by arguing that scientists were doing an important job, and they should not be blamed because they needed to travel, even though it implies emitting carbon to the atmosphere. This objection started a longer discussion on where responsibility lies and what it means to reduce flying (for whom, what kind of flights, how much does it matter). It also led to an expansion of the frequent flyer card story, not only making it about personal change but contextualising it, adding details on how academia as a whole responded to its excessive flying habits.

Most participants, however, referred to their engagement as a hopeful experience, remarking on a current of dry humour in the exhibition materials which they felt made it easier to scrutinise our present world and habits. It was important to dwellers that the path towards a postfossil society was outlined, but that the way the transition unfolded was left open so that they could specu- late on it and propose changes. Another important aid to active participation as a dweller is that the stories that make up Carbon Ruins are stories of a transition that has already happened:

Carbon Ruins is a journey of transformation. How did we get here? Most of the time it is the other way around. You take small steps forward. Now we have already arrived here. It feels good to start from the future. Not being able to postpone the future, some decisions. Something changes when you think like that. (Policy officer, interview, Lund municipality)

Many participants also expressed an appreciation for the opportunity to contribute to world-building, with one praising the format's encouragement of speculation: "It allows you to think big" (anonymous person at one of the guided tours in Lund). But not all participants felt it was easy to contribute to world-building. A perceived lack of expertise and knowledge of the climate impact of various practices inhibited some dwellers' imagination, despite there already being a world in place to relate to:

It was difficult to contribute with stories because you feel like you don't know enough! It felt hard to substantiate. It would be rewarding to do the whole thing again, with people with different competencies and perspectives who can contribute with different kinds of stories. To have a mixed group would have been very interesting. (Policy officer, Malmö municipality)

Other visitors expressed feelings of anxiety about the magnitude of the climate crisis, and wondered whether we are at all capable of handling it in any meaningful way. This, of course, also affected their engagement with Carbon Ruins, and prevented a complete absorption in the storyworld. This points to the need for further facilitation to achieve a deeper sense of engagement among various participants.

\subsection{Explorers}

A few participants stood out as engaging particularly deeply with the Carbon Ruins world. These participants, here referred to as explorers, went further than the dwellers by adding new fragments to the Carbon Ruins world and thus expanding its scope. Explorers typically engaged in workshops or performances, during or after visiting the exhibition.

Many explorers reacted to a perceived lack of pain and suffering in the narrative of the transition years and produced stories of inequality and unjust transition. One example was the suggestion of adding barbed wire as an object in the exhibition. The barbed wire would be a symbol of borders, and the horrible migration politics of the EU during the transition years. The story imagines a heat wave across the Iberian Peninsula in 2035, which leads to the collapse of the agricultural system in Europe, and a 
large number of people fleeing to the north, which eventually mobilises a movement for a more humanitarian migration politics.

Another example is a letter sent to a (fictive) local Swedish newspaper which had favourably reviewed the Carbon Ruins exhibition. A middle-aged woman remembers how the famine she experienced during her youth made her infertile, and the reason she thought she would have for celebrating the transition-that a post-fossil world would allow her children and their children the possibility to live a good life-was stolen from her:

For my own village the story was one of unimaginable pain. We depended upon fossil-fuel-based food systems. In the great agricultural transition, the food shortages of Europe pushed the rural marginalised further away from access to food. My family and I were forced to beg for handouts from the state, which in a changing climate was insecure and hungry. I saw neighbours flee the villages - to better times in suburban slums of rapidly growing cities. But most of all I saw anger. We had not caused this crisis-why were we to pay with the forced genocide of rural cultures? (Researcher, Uppsala University)

Explorer authorship was also facilitated by the workshops, in which groups from the same workplace or organisation had the chance to collectively formulate their transition story. One group from the Swedish Church expressed that the exercise of writing their story made them dare to think about what they really wanted, what the role of the Church really is in making sense of climate change. Their story was one of shifting theology:

We returned to our eco-theological roots. Everything alive is part of God's creation. When the church loses money, it is seen as a release from the claws of capitalism. We share our economy....When you are buried your body becomes an organic bag in which you can plant a tree. We are co-creators in God's creation.

Not only does the Carbon Ruins world, then, provide a sense that post-fossil futures are possible, it might also, at least for some participants, invoke a kind of hope related to action:

How do we talk about the future, is it bright or dark? What does that mean? The exhibition gives hope about the future, but it is also important to realise that we need to do things now if these visions are to be reached. What can we do to contribute? (Officer, interview, Church of Sweden)

The explorers were characterised by a will to take ownership of post-fossil transition stories. Their many amendments to the perceived lack of painful stories in the Carbon Ruins world points to the importance of including a multiplicity of stories about the transition, each one describing different victories, struggles, and sufferings that are relatable to different kinds of audiences.

\section{Towards Imaginative Engagements with Climate Politics}

The sites where a carbon-constrained world is represented and acted upon are nowadays everywhere, from the UN to the bike lane, from the boardroom to the courts and the supermarket. And yet, long-term decarbonised futures are seldom situated and made palpable. Carbon Ruins proposes a methodology for crafting a space where imaginative, as well as tangible, engagement with a post-fossil world can emerge. It does so by problematising contemporary social practices by defamiliarizing them, provoking imagination and critical self-reflection through the sharing of stories and memories around particular artefacts. Carbon Ruins is a kind of 'experiential future' (Candy, 2010), a process of co-creating a post-fossil world, which invites participants to experience fragments of a future, to alter them, and to create new fragments. The fact that participants were able to continually alter and expand on the world led to a "blurring [of] the distinction between audience and authorship" (Wolf, 2012, p. 281). We observed, in general, three broad kinds of authorship (originators, dwellers, and explorers), and many different forms of engagement.

While many future-imagining exercises invite participants, as originators, to start building the world while it is still open, often that world is then subsequently offered as ready-made-a new status quo that cannot be changed, only reacted to. In this article we have reflected on what happens when people are instead invited to become active in changing and inhabiting a world (dwellers) and to expand on it (explorers). The concreteness of things happening in our subcreated world, and the fact that stories about innovation, change, and resistance were always populated by particular agents (people, organisations, movements, etc.), spurred discussions about things that we take for granted about the present world, what might be done about them, and what kind of society is even desirable. We found that dwellers were able to supplant a passive sense of urgency with 'active hope.' For those who had the chance to take the role of explorer, a sense of resignation could be turned into active commitment and determination. A crucial question is, of course, to what extent this sense of agency can translate into action in the 'primary world' after they have ended their experience with the 'secondary world' of Carbon Ruins? Candy argues that a:

Deepening engagement with the domain of the future does progressively engender a form of political engagement, a heightened sensitivity to the mutability of the world, and with that, a sense of one's own capacity, however modest, to nudge things in one direction or other. (Candy, 2010, p. 164) 
Thus, participatory engagement with an imaginary world such as Carbon Ruins not only provokes retrospection and self-reflection, but might also inspire participants to view themselves as agents of change and, eventually, spark people to act on the basis of their engagement with the future.

This approach of immersion in, and co-creation of, an imaginary post-fossil world did not, however, engage every visitor. For instance, we observed visitors that did not appreciate the openness and vagueness of the world. Others were unable to engage emotionally because of feelings of hopelessness. Such reactions are reasonable in world-building for those who find it difficult, or perhaps even irresponsible, to achieve the necessary suspension of disbelief. That some visitors felt unable to engage imaginatively is understandable considering both the incompleteness of the imaginary world and the present power structures that are driving the climate crisis in the first place. Even so, this drove us to reflect on how to engage as many people as possible. First, a lesson learned from our experience with Carbon Ruins is the importance of presence. As hosts, we were responsible for facilitating world-building. We found that participants need guidance and prompts that trigger them to enter the world and to participate in the collective process. Second, imaginary world-building relies, as other kinds of storytelling and narration do, on the credibility and authenticity of the storyworld. The stories being told about this world enrich it partly through being consistent with it. To make these stories reliable, 'facts' and knowledge-based claims drawn from the present world are critical, especially when participants feel they do not know enough. The openness of the storyworld not only enabled shared authorship among participants; it also provided leeway for accommodating reservations and objections along the way, and formed a basis for revising and updating the stories. This allowed participants to openly dispute facts and object to ideas they did not find credible, which made them more able to engage with the post-fossil world even though their immersive experience was not successful.

When Carbon Ruins encourages its different audiences to reflect on what happened during the transition years, it reconstructs a 'history of the future present' (Adam, 2010) that resembles what Foucault considered the critical potential of historical methods: to disturb what was previously considered immobile; to fragment what was thought unified (Foucault, 1984, p. 82). Garland (2014, p. 372) describes the 'genealogical analysis' as one which traces how "contemporary practices and institutions emerged out of specific struggles, conflicts, alliances, and exercises of power, many of which are nowadays forgotten." Through the device of a fictional museum set in the future, Carbon Ruins urges its authors, as originators, dwellers, and explorers, to 'remember' how the post-fossil present came into being. We find that the authoring of such stories and histories is a powerful method for thinking about how the future might be configured otherwise. Carbon Ruins is not about the search for an absolute origin, a grand beginning, or, in our case, a closed and predestined scenario for the transition to a post-fossil future. Rather, it is about descent and emergence; the collaborative piecing together of separate dispersed events and practices to form a contingent post-fossil future present.

\section{Acknowledgments}

This article is the work of the authors listed, but it discusses a complex and collaborative undertaking that deserves to be acknowledged in full. The Carbon Ruins exhibition is the result of several initiatives at Lund University, Sweden (LU), most notably the Narrating Climate Futures initiative (funded by the LU ViceChancellor), the Climaginaries project (funded by the Swedish Research Council FORMAS), and the think tank LU Futura (funded by the LU Vice-Chancellor). The core group who crafted the exhibition included Ludwig Bengtsson Sonesson (LU Sustainability Forum), Roger Hildingsson, Sylvia Lysko, Johannes Stripple (Department of Political Science, LU), Caroline Mårtensson (independent artist), and Alexandra Nikoleris (Department of Technology and Society, LU). Karl Holmberg and Paul Graham Raven (Department of Political Science, LU) deserves special mention, as does Valentin Vogl (Department of Technology and Society, LU), for extensive participation in storycrafting and initial worldbuilding. The guided tours and the participatory workshops were convened by Ludwig, Roger, Alexandra, Johannes, and Anna Romeling. We are immensely thankful for all the creative work that members of the abovementioned initiatives and projects, and research colleagues and practitioners in the expert workshops, put into crafting the stories, characters, and events which make up the Carbon Ruins storyworld. We also thank all visitors who have engaged with and helped develop this world even further. Finally, we are grateful for valuable comments by two anonymous reviewers, as well as our copy editor Katrina Zaat, who not only improved the language of our manuscript but also challenged some of our ideas. Read more about Carbon Ruins here: www.climaginaries.org/carbon-ruins

\section{Conflict of Interests}

The authors declare no conflict of interests.

\section{References}

Adam, B. (2010). History of the future: Paradoxes and challenges. Rethinking History, 14(3), 361-378.

Andersson, J. (2018). The future of the world: Futurology, futurists, and the struggle for the post-cold war imagination. Oxford: Oxford University Press.

Beckert, J. (2016). Imagined futures: Fictional expectations and capitalist dynamics. Cambridge, MA: Har- 
vard University Press.

Bendor, R., Maggs, D., Peake, R., Robinson, J., \& Williams, S. (2017). The imaginary worlds of sustainability: Observations from an interactive art installation. Ecology and Society, 22(2). https://doi.org/10.5751/ ES-09240-220217

Bernstein, S., \& Hoffmann, M. (2019). Climate politics, metaphors and the fractal carbon trap. Nature Climate Change, 9, 919-925.

Burchell, G. (1996). Liberal government and techniques of the self. In A. Barry, T. Osborne, \& N. Rose (Eds.), Foucault and political reason: Liberalism, neo-liberalism and rationalities of government (pp. 19-36). Chicago, IL: University of Chicago Press.

Candy, S. (2010). The futures of everyday life: Politics and the design of experiential scenarios (Unpublished Doctoral dissertation). University of Hawaii at Mānoa, Honolulu, USA.

Candy, S., \& Dunagan, J. (2017). Designing an experiential scenario: The people who vanished. Futures, 86, 136-153.

Crawford, N. C. (2003). Feminist futures. In J. Weldes (Ed.), To seek out new worlds: Science fiction and world politics (pp. 195-220). London: Palgrave McMillan.

Dean, M. (2004). Governmentality: Rower and rule in modern society ( $2 \mathrm{nd}$ ed.). London and Thousand Oaks, CA: SAGE.

Death, C. (2014). Critical, environmental, political: An introduction. In C. Death (Ed.), Critical environmental politics (pp. 1-12). Abingdon: Routledge.

Foucault, M. (1984). Nietzsche, genealogy, history. In P. Rabinow (Ed.), The Foucault reader (pp. 76-100). New York, NY: Pantheon Books.

Garland, D. (2014). What is a "history of the present"? On Foucault's genealogies and their critical preconditions. Punishment \& Society, 16(4), 365-384.

Ghosh, A. (2017). The great derangement: The crisis of imagination in the era of climate change. Chicago, IL: University of Chicago Press.

Hajer, M. A., \& Pelzer, P. (2018). 2050: An energetic odyssey-Understanding 'techniques of futuring' in the transition towards renewable energy. Energy Research \& Social Science, 44, 222-231.

Hesselgren, M., Eriksson, E., Wangel, J., \& Broms, L. (2018). Exploring lost and found in future images of energy transitions: Towards a bridging practice of provoking and affirming design. In S. Storni, K. Leahy, M. McMahon, E. Bohemia, \& P. Loyd (Eds.), Proceedings from Design Research Society Conference DRS 2018 (pp. 941-954). Limerick: Catalyst.

Holland, N. N. (2009). Literature and the brain. Gainesville, FL: The PsyArt Foundation.

Levitas, R. (2013). Utopia as method: The imaginary reconstitution of society. London: Springer.

Linnér, B.-O., \& Wibeck, V. (2019). Sustainability transformations: Agents and drivers across societies. Cambridge: Cambridge University Press.

Linnér, B.-O., \& Wibeck, V. (2020). Conceptualising variations in societal transformations towards sustainability. Environmental Science and Policy, 106, 221-227.

Muiderman, K., Gupta, A., Vervoort, J., \& Biermann, F. (2020). Four approaches to anticipatory climate governance: Different conceptions of the future and implications for the present. WIREs Climate Change, 11(6). https://doi.org/10.1002/wcc.673

Nordin, I. (2010). Science fiction och filosofi [Science fiction and philosophy]. In M. Godhe \& J. Ramsten (Eds.), Möjliga världar: Tekniken, vetenskapen och science fiction [Possible worlds: Technology, science and science fiction] (pp. 101-115). Stockholm: Carlssons.

Pelzer, P., \& Versteeg, W. (2019). Imagination for change: The post-fossil city contest. Futures, 108, 12-26.

Robinson, J. (2003). Future subjunctive: Backcasting as social learning. Futures, 35, 839-856.

Suvin, D. (1979). Metamorphoses of science fiction: On the poetics and history of a literary genre. New Haven, CT: Yale University Press.

Tolkien, J. R. R. (1947). On fairy-stories. In C. S. Lewis (Ed.), Essays presented to Charles Williams (pp. 38-89). London: Oxford University Press.

Wangel, J. (2012). Making futures: On targets, measures and governance in backcasting and planning for sustainability (Unpublished Doctoral dissertation). KTH Royal Institute of Technology, Stockholm, Sweden.

Wangel, J., Hesselgren, M., Eriksson, E., Broms, L., Kanulf, G., \& Ljunggren, A. (2019). Vitiden: Transforming a policy-orienting scenario to a practiceoriented energy fiction. Futures, 112. https://doi. org/10.1016/j.futures.2019.102440

Weldes, J. (2003). Popular culture, science fiction, and world politics. In J. Weldes (Ed.), To seek out new worlds: Science fiction and world politics (pp. 1-27). London: Palgrave McMillan.

Wolf, M. J. P. (2012). Building imaginary worlds: The theory and history of subcreation. New York, NY: Routledge.

\section{About the Authors}

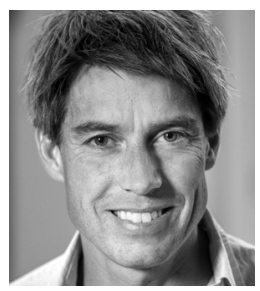

Johannes Stripple is an Associate Professor in Political Science at Lund University, Sweden. His research has traced the governance of climate change through a range of sites, from the UN to the everyday, from the economy, the urban, and the low carbon self. He has edited Governing the Climate: New Approaches to Rationality, Power and Politics (Cambridge University Press, 2014) and Towards a Cultural Politics of Climate Change (Cambridge University Press, 2016). 


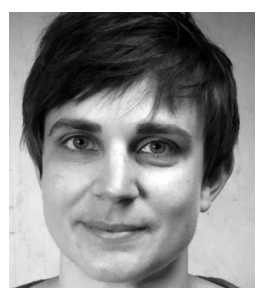

Alexandra Nikoleris is an Associate Senior Lecturer in Environmental and Energy System Studies at Lund University. She defended her thesis On the Role of Envisioned Futures in Sustainability Transitions in 2018. Her research focus is on futuring and how futures, in a broad sense, are being used in different ways to enable processes of change with a specific interest in the linkages between artistic and 'scientific' futures.

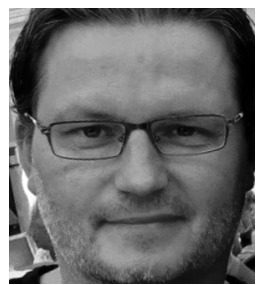

Roger Hildingsson is a Senior Researcher in Political Science at Lund University, Sweden. His research focuses on environmental politics, sustainability governance and the governing of climate change at various sites, as well as on the green state, urban sustainability, industrial decarbonisation, and the transition to post-fossil futures. His works is published in a number of edited volumes and journals such as Environmental Politics, Environmental Policy and Governance and Futures. 